\title{
O Protagonismo Político e Social do Movimento Nacional de Catadores de Materiais Recicláveis na Efetivação de Direitos Fundamentais
}

\author{
Priscila Tinelli Pinheiro \\ Doutora e Mestre em Direitos e Garantias Constitucionais pela Faculdade de Direito de Vitória (FDV). Membro do Grupo \\ de Pesquisa "Invisibilidade Social e Energias Emancipatórias em Direitos Humanos" da Faculdade de Direito de Vitória (FDV). \\ Advogada. priscilatinelli@hotmail.com

\section{Gilsilene Passon P. Francischetto} \\ Pós-doutora pelo Centro de Estudos Sociais da Universidade de Coimbra (2008), sob a orientação do Professor Doutor Boaventura \\ de Sousa Santos. Professora titular na Graduação, Pós-Graduação, Mestrado e Doutorado e orientadora do Grupo de Pesquisa \\ "Invisibilidade Social e Energias Emancipatórias em Direitos Humanos" da Faculdade de Direito de Vitória (FDV). \\ gilsilenepasson@uol.com.br
}

O presente artigo propõe-se a analisar, por meio da abordagem dialética, o protagonismo exercido pelo Movimento Nacional de Catadores de Materiais Recicláveis (MNCR) na efetivação dos direitos fundamentais à saúde, à moradia e à educação. Desenvolvendo suas atividades nas ruas ou na modalidade associativa, esses trabalhadores enfrentam diversas dificuldades intrínsecas à sua atividade laborativa, as quais se agravam pelo fato de vivenciarem um contexto de repleta negação de direitos. Isso posto, pretende-se discutir a importância dos movimentos sociais para a conquista de direitos, em especial a atuação daqueles classificados como "novos", na construção teórica de Maria da Glória Gohn (2013), como é o caso do MNCR, seguido pela análise das principais questões relativas aos direitos fundamentais à saúde, à moradia e à educação como objetivos traçados pelo Movimento para representar a categoria profissional. Por último, estuda-se o contexto atual dos catadores de materiais recicláveis por meio dos avanços obtidos na efetivação dos direitos em tela.

Palavras-chave: Movimentos sociais. Catadores de materiais recicláveis. Saúde. Educação. Moradia.

THE POLITICAL AND SOCIAL PROTAGONISM OF THE NATIONAL MOVEMENT OF CATCHERS OF RECYCLABLE MATERIALS IN THE EFFECTIVENESS OF FUNDAMENTAL RIGHTS

\section{ABSTRACT}

This article proposes to analyze, through the dialectical approach, the role played by the National Movement of Collectors of Recyclable Materials (MNCR) in the realization of fundamental rights to health, housing and education. By developing their activities in the streets or in the associative mode, these workers face several difficulties intrinsic to their work activity, which are aggravated by the fact of experiencing a context of full denial of rights. In order to do so, it is intended to discuss the importance of social movements for the conquest of rights, especially the performance of those classified as "new", in the theoretical construction of Maria da Glória Gohn (2013), as is the case of MNCR. Followed by the analysis of the main issues related to the fundamental rights to health, housing and education as objectives drawn by the movement to represent the professional category. Finally, the current context of collectors of recyclable materials is analyzed through the advances obtained in the realization of the rights on canvas.

Keywords: Social movements. Collectors of recyclable materials. Health. Education. Housing.

SUMÁRIO

1 Introdução. 2 A "nova" face dos movimentos sociais. 3 O histórico de lutas do MNCR no cenário nacional e os direitos fundamentais objetivados. 3.1 Saúde, educação e moradia como objetivos do MNCR e sua atuação. 4 Considerações finais. 5 Referências. 


\section{Humanos e \\ Democracia}

\section{INTRODUÇÃO}

Em 2010, com a promulgação da Política Nacional de Resíduos Sólidos (Lei 12.305), a reciclagem ganhou visibilidade no cenário brasileiro. A partir das diretrizes legislativas, a tendência era de que o trabalho dos catadores de materiais recicláveis, na condição de ramificação do processo de reciclagem e de reaproveitamento de resíduos, passasse a ser valorizado, o que não ocorreu por completo em decorrência dos variados entraves enfrentados na prática por estes trabalhadores, inclusive para a efetivação de seus direitos mais básicos.

Com o crescimento da população, o problema dos resíduos urbanos produzidos pela sociedade tomou grande proporção, o que se transformou em uma situação insustentável tanto para a população quanto para o Estado. Neste contexto, houve a necessidade de investimentos na atividade de reciclagem, o que permitiu o avanço das técnicas empregadas em tal ação e a tornou altamente lucrativa.

Além do trabalho voltado para a conscientização da população acerca da necessidade de efetuar uma coleta seletiva, nota-se que a atividade desenvolvida pelo catador - que culmina, em um segundo momento, na formação de associações de catadores de materiais recicláveis - faz parte de um processo muito maior de busca por alternativas ao desemprego e à lógica de exclusão do capitalismo.

Com base nas proporções alcançadas pela atividade de reciclagem, os próprios recicladores tomaram a iniciativa da criação de uma entidade, que tivesse como principal função resguardar o trabalho desenvolvido pelo catador por meio da busca pela efetivação junto ao poder público dos direitos daqueles que exercem tal atividade. Houve necessidade de organização e luta social diante das inúmeras lesões a direitos humanos, além do processo de discriminação do qual são vítimas.

Para tanto foi criado o $\mathrm{MNCR},{ }^{1}$ que hoje se constitui em um verdadeiro órgão de fomento à atividade de reciclagem, em especial resguardando os direitos dos catadores. O protagonismo assumido desde a sua constituição é fundamental na luta diária enfrentada por estes trabalhadores, pois um de seus principais objetivos é justamente a efetivação de direitos dos seus membros.

Nesse sentido, o movimento busca a concretização de direitos como a moradia, a saúde e a educação dos catadores, os quais estão previstos na Constituição Federal de 1988, em seu artigo 5으, como direitos e garantias fundamentais do cidadão brasileiro. Além disso, incentiva-se que os catadores que atuam nas ruas associem-se e, com isso, fujam dos problemas enfrentados pelo exercício do recolhimento nas vias públicas.

Diante deste cenário de lutas, tendo em vista os objetivos almejados pelo MNCR, quais sejam, o direito à moradia, saúde e educação, de que formas as ações do referido coletivo têm contribuído para a sua efetivação?

\footnotetext{
O Movimento Nacional dos Catadores de Materiais Recicláveis (MNCR) é um movimento social que "[...] surgiu em meados de 1999 com o 1 ㅇ Encontro Nacional de Catadores de Papel, sendo fundado em junho de 2001 no 1 10 Congresso Nacional dos Catadores(as) de Materiais Recicláveis em Brasília, evento que reuniu mais de 1.700 catadores e catadoras" (MNCR, 2018f, p. 2).
} 


\section{A "NOVA" FACE DOS MOVIMENTOS SOCIAIS}

Com o objetivo de compreender de maneira adequada o surgimento das organizações sociais formadas pelos catadores de materiais recicláveis, a análise do presente tópico iniciar-se-á pela categorização dos "novos" movimentos sociais e, neste ponto, diferenciando-os dos primeiros surgidos no Brasil para chegar, então, à identificação das formas de organização pelas quais os catadores pleiteiam seus direitos perante o Estado.

Ressalta-se que os movimentos sociais estão cada vez mais presentes na sociedade e a sua importância para o fortalecimento de grupos sociais, em especial aqueles que se encontram excluídos, é notável. No atual contexto, entretanto, observam-se algumas características que os diferenciam dos "velhos" movimentos sociais - anteriores à década de 70 - e conferem uma nova roupagem às formas de articulação adotadas por eles em busca da afirmação de suas ações.

No que tange às principais mudanças adotadas pelos denominados "novos" movimentos sociais em relação ao passado, Maria da Glória Gohn (2013, p. 15) destaca que, agora, é preciso classificar o tipo de ação coletiva utilizada para caracterizar uma modalidade de movimento social, pois "[...] estas ações [...] tanto podem ter caráter emancipatório e transformador, como meramente integrativo e conservador" (GOHN, 2013, p. 8).

Este caráter integrativo e conservador mencionado pela autora está bastante presente nos movimentos sociais das décadas de 80 e 90, pois naquela época era comum que sua organização não partisse dos próprios requerentes dos direitos, mas sim de terceiros, como os sindicatos, as ONGs, as Igrejas, etc.

De outra banda, aparece o caráter emancipatório e transformador, o qual predomina nas novas movimentações e tem, por consequência, a elevação dos integrantes das categorias sociais a sujeitos políticos. Isso significa que os atores sociais pertencentes aos grupos que pleiteiam direitos perante o Estado começam a exercer de forma mais explícita - uma vez que adquirem autonomia no sentido de capacidade organizativa própria - sua cidadania na forma coletiva.

Tornam-se, deste modo, sujeitos ativos de seus próprios movimentos de luta sem, por outro lado, precisarem seguir uma pauta de reivindicações predefinida por um grupo alheio aos seus anseios e angústias. Nos "novos" movimentos sociais predomina, então, um "[...] distanciamento do caráter classista que se configurava nos 'velhos movimentos sociais' (movimentos sindicais e operários, localizados no mundo do trabalho)" (HERKENHOFF, 2004, p. 16).

Entende-se que o conceito de cidadania possui, basicamente, duas dimensões: a individual - que neste momento não será objeto deste estudo - e a coletiva. À cidadania coletiva podem ser atribuídos dois marcos referenciais, os quais, na visão de Maria da Glória Gohn (2013, p. 195-196), podem ser descritos da seguinte forma:

O primeiro remete às origens clássicas do cidadão da polis grega, pois diz respeito a uma dimensão cívica, em que os cidadãos exercitam virtudes cívicas e têm na comunidade em que vivem a sua referência imediata. Há obrigações e deveres a cumprir. $O$ segundo marco remete à contemporaneidade, ou aos tempos pós-modernos. Ela diz respeito à busca de leis e direitos para categorias sociais até então excluídas da sociedade, principalmente do ponto de vista econômico (lutas pela terra a partir de favelados, por exemplo, categoria social antes considerada como marginal ao sistema econômico, hoje vista como parte 


\section{Democracia}

dele, como bolsão da miséria e do subemprego), e do ponto de vista cultural (lutas contra a exclusão social de certas categorias sociais, como as mulheres, as minorias étnicas, etc.). Assim, a cidadania coletiva privilegia a dimensão sociocultural, reivindica direitos sob a forma da concessão de lei; reivindica espaços sociopolíticos sem que para isto tenha de se homogeneizar e perder sua identidade cultural.

Identifica-se este segundo marco referencial da cidadania coletiva, ou seja, a busca por leis e direitos para aqueles grupos sociais que se encontram excluídos da sociedade moderna, como o exemplo do movimento protagonizado pelos catadores de materiais recicláveis. Trata-se de uma categoria de trabalho formada por típicos atores da exclusão social, os quais encontraram na atividade de catação, seja nas ruas ou nas associações e cooperativas, uma alternativa ao desemprego estrutural na busca pela sobrevivência.

Outro ponto eleito pela autora para retratar as novas características assumidas pelos movimentos sociais consiste no fato de que

Naquela época os movimentos lutavam para ter "direito a ter direitos". Como só podemos falar em direitos se contemplamos o universal, aqueles movimentos não estavam autocentrados, não miravam apenas a si próprios [...] olhavam para o outro, até para poderem construir a própria identidade [...] (GOHN, 2013, p. 17).

Isso se explica pelo fato de os primeiros movimentos sociais terem surgido no Brasil em plena ditadura militar, época em que vigia a repressão social e não se permitia qualquer manifestação contrária ao poderio estatal. Assim, antes de promover alguma reivindicação para o grupo, era preciso conquistar o direito de se opor às determinações dos governantes.

Superada esta etapa de conquista de voz perante o poder público, os "novos" movimentos sociais enfrentam o atual desafio de efetivação dos direitos já assegurados pelo Estado por meio de seus instrumentos legais. Além disso, pleiteiam-se "[...] novas culturas políticas de inclusão, contra a exclusão" (GOHN, 2013, p. 16), com o fim de tornar a sociedade mais igualitária sem, contudo, ultrapassar os limites das diferenças entre os grupos sociais, as quais são responsáveis por preservar suas identidades.

Observa-se, dessa forma, que um movimento social não se resume a uma mera organização de indivíduos integrantes de determinado grupo social, mas vai muito além dessa situação. Um movimento social deve ser organizado para lutar por transformações e, sobretudo, deve conferir autonomia para os seus membros.

Assim, os movimentos sociais se diferenciam das ações cívicas pelo fato de que

eles mobilizam ideias e valores e geram saberes e aprendizado coletivo; enquanto isso, a maioria das chamadas ações cívicas são organizadas de cima para baixo, permanecem autocentradas e autorreferenciadas, limitando-se ao desempenho de uma estratégia de sobrevivência ou uma ação cultural, sem desenvolver, na maioria das vezes, potencial para autonomia ou autodesenvolvimento das ações (GOHN, 2013, p. 41).

A partir destas ressalvas nota-se que "os movimentos sociais, populares ou não, expressaram a construção de um novo paradigma de ação social, fundado no desejo de se ter uma sociedade diferente, sem discriminações, exclusões ou segmentações" (GOHN, 2013, p. 203).

João Baptista Herkenhoff (2004, p. 25) atribui a seguinte função aos "novos" movimentos sociais, em especial àqueles promovidos no cerne da sociedade brasileira: 
Os movimentos sociais não se submetem aos padrões do Direito estabelecido. Sobretudo em sociedades, como a brasileira, onde milhões de pessoas estão à margem de qualquer direito, num estado de permanente negação da Cidadania, os movimentos sociais estão sempre a "criar direitos" à face de uma realidade sociopolítica surda aos apelos de direito e dignidade humana.

É, em busca da criação e da efetivação de direitos, que os "novos" movimentos sociais passaram a ser organizados por aqueles excluídos do âmbito normativo. Numa tentativa de se fazerem novamente presentes na sociedade civil, estes indivíduos estão cada vez mais angariando forças e se reunindo em torno de condições dignas de vida, as quais compreendem as esferas do trabalho, educação, saúde, entre outras.

De acordo com Maria da Glória Gohn (2013, p. 31), torna-se possível identificar um movimento social, cujas ações adquirem expressividade perante a comunidade quando ele

[...] não assume ou "veste" uma identidade pré-construída apenas porque tem uma etnia, um gênero ou uma idade. Este ato configura uma política de identidade e não uma identidade política. $O$ reconhecimento da identidade política se faz no processo de luta, perante a sociedade civil e política; não se trata de um reconhecimento outorgado, doado, uma inclusão de cima para baixo. O reconhecimento jurídico, a construção formal de um direito, para que tenha legitimidade, deve ser uma resposta do Estado à demanda organizada.

Luta-se, portanto, por uma afirmação perante o poder estatal a partir de suas próprias bases e características com o objetivo de conferir maior legitimidade ao seu pleito e, por conseguinte, adquirir representatividade.

Nesta perspectiva, pode-se afirmar que

[...] as ações coletivas dos movimentos sociais não criaram valores novos, mas apenas redefiniram os já existentes, a partir do resgate de valores, já seculares como os dos direitos humanos, da cidadania, da liberdade de expressão e da autonomia. Estes valores foram resgatados de ideários de diferentes matrizes epistemológicas, e de visões de mundo até conflitantes no passado, como a autonomia dos anarquistas e a liberdade e a cidadania dos liberais (GOHN, 2013, p. 204).

Com base na conquista de espaço que as ações protagonizadas pelos movimentos sociais obtiveram ao longo da história, o próximo tópico analisará o protagonismo destas organizações no que respeita ao movimento social de maior expressividade na categoria dos catadores de materiais recicláveis, qual seja, o MNCR. Assim, o referido movimento apresenta-se como um exemplo no âmbito nacional destes "novos" movimentos sociais.

\section{HISTÓRICO DE LUTAS DO MNCR NO CENÁRIO NACIONAL E OS DIREITOS FUNDAMENTAIS OBJETIVADOS}

Ao traçar um paralelo entre as considerações tecidas acerca dos movimentos sociais e a realidade vivenciada pelos catadores de materiais recicláveis, vislumbra-se a importância de uma organização por parte desta categoria em prol da efetivação de seus anseios, haja vista a vulnerabilidade e a ausência de representatividade política que a atuação de maneira isolada encontra. 


\section{Democracia}

As próprias peculiaridades da atividade de coleta contribuem para o isolamento do grupo dos catadores, uma vez que ela se originou como

[...] uma atividade complementar, desenvolvida pela população de rua entre as décadas de 1980 e 1990. As características dessa atividade e daqueles que a executam condizem com baixos níveis de escolaridade, alta taxa de rotatividade, segmentarização dos vínculos e precariedade do trabalho (BORTOLI, 2013, p. 249).

Justificam-se as lutas promovidas pelos representantes dos catadores nos movimentos sociais, pois mesmo que o cenário tenha sofrido modificações significativas, em virtude de inúmeras ações coletivas desenvolvidas pelos próprios catadores, do grande valor assumido pelo processo de reciclagem na sociedade e pela disseminação do associativismo, a realidade enfrentada por eles ainda é precária. Estima-se que há, atualmente, no Brasil,

[...] em torno de um milhão de pessoas que sobrevivem com a coleta de materiais recicláveis, seja na catação de rua ou nos lixões. E [...] cerca de 65 mil catadores estão organizados em aproximadamente 600 cooperativas ou associações, constituindo a base do movimento (BENINCÁ, 2012).

Entre as dificuldades enfrentadas pelos "novos" movimentos sociais, Antônio Carlos Wolkmer atribui às consequências da adoção do capitalismo nas sociedades periféricas, como a brasileira, o fato de que o pleito destas organizações recaia, quase que exclusivamente, sobre os direitos mais basilares dos indivíduos. De acordo com o autor,

[...] quando se examinam atentamente as sociedades centralizadoras e dependentes do capitalismo periférico, como a realidade brasileira, sacudida por virulentas desigualdades sociais, exploração econômica e dominação política, percebe-se ampla gama de conflitos coletivos, muitos dos quais originados por reivindicações que refletem, basicamente, carências materiais e necessidades por direitos essenciais (WOLKMER, 2001, p. 105).

Este contexto decorre do fato de que muitos dos direitos mínimos não são concretizados pelo Estado, fazendo-se necessária a organização dos grupos sociais que não os usufruem para lutar pela sua efetivação. São verdadeiros obstáculos à ampliação da pauta de reivindicações, na medida em que os direitos basilares, previstos no ordenamento jurídico, deveriam ser estendidos a todos e apenas aqueles específicos de cada grupo social serem pleiteados perante o poder público, quando o que se observa é o inverso.

Diante deste cenário de ausência de concretização dos direitos básicos, os catadores de materiais recicláveis começaram a se organizar na década de 80 , em âmbito regional, a fim de viabilizar ações coletivas em prol do reconhecimento da categoria. Desta forma, "[...] apesar de se registrar o trabalho dos catadores ou o trabalho dentro e fora dos lixões brasileiros desde o fim do século XIX, somente no fim da década de 80, iniciam-se as articulações para tratar das questões específicas ao segmento" (BENVINDO, 2010, p. 42).

Em 1998 criou-se o Fórum Nacional Lixo e Cidadania, o qual contou com a coordenação do Fundo das Nações Unidas para a Infância (Unicef) e teve como finalidade a "[...] erradicação do trabalho infantil com o lixo em todo o país, com o lançamento da campanha Criança no Lixo Nunca Mais" (IPEA, 2013, p. 29). 
O Fórum teve por enfoque, "[...] além da erradicação do trabalho infantil nos lixões a céu aberto, a capacitação dos catadores para atuarem no gerenciamento dos resíduos sólidos com condições seguras e dignas de trabalho e a garantia de sua inclusão social e cidadania" (IPEA, 2013, p. 29-30).

Atualmente, o Fórum está presente nas esferas nacional, estadual e municipal, nos quais "o objetivo de mudança do olhar da sociedade para com esta categoria [...]" (BENVINDO, 2010, p. 42) é ainda maior, uma vez que eles trabalham com a finalidade "[...] de pautar governo, imprensa e formadores de opinião sobre as especificidades do universo do trabalho dos catadores" (2010, p. 42).

Além do surgimento do referido Fórum, aponta-se que a primeira organização dos catadores em âmbito nacional, o Movimento Nacional de Catadores de Materiais Recicláveis (MNCR), foi criada em 2001. Hoje, este Movimento "[...] é reconhecido como a maior organização nacional de defesa dos interesses dos catadores do mundo, e ao longo dos anos conseguiu estender suas articulações para outros países" (IPEA, 2013, p. 30).

No que se refere às especificidades do Movimento, bem como a sua pauta de reivindicações perante o poder estatal, Benvindo (2010, p. 43) explicita que:

O MNCR configura-se enquanto um movimento social em defesa dos interesses da categoria dos catadores, tendo como bandeira fundamental o reconhecimento e valorização dos mesmos enquanto trabalhadores. A organização preconiza a integração formal do contingente de catadores nos sistemas públicos de tratamento de resíduos sólidos, bem como a remuneração destes pelo serviço público que prestam, como já acontece em algumas localidades.

A constituição de bases fixas para a construção do movimento foi essencial para a consolidação da categoria dos catadores, sendo notável, no entanto, que a situação dos catadores ainda necessita de muitas lutas em busca da efetivação de mais direitos sociais, o que, de forma coletiva, permitirá a obtenção de resultados mais expressivos para o grupo.

Após o estabelecimento do MNCR, ocorreram outras formas de organização dos catadores, podendo ser citada a título exemplificativo a organização do Festival Lixo e Cidadania, em 2002, realizado na cidade de Belo Horizonte, o qual está atualmente na sua 13a edição. Segundo o Relatório do Ipea sobre a Situação dos Catadores de Materiais Recicláveis redigido no ano de 2013, o Festival teve grande relevância na disseminação das questões dos catadores das mais variadas regiões do país, uma vez que se tornou um "espaço de encontro e discussão de temáticas importantes para a categoria, além de permitir a celebração e a congregação entre eles, fortalecendo sua identidade nacional" (IPEA, 2013, p. 32).

Para os sujeitos que se encontram excluídos da sociedade e enfrentam entraves na efetivação dos seus direitos fundamentais, é imprescindível a constituição de organizações coletivas para a conquista, ou mesmo efetivação de direitos. Percebeu-se, então, que o Movimento Nacional dos Catadores de Materiais Recicláveis é essencial para a constante luta desta categoria perante não só o poder público, mas diante de toda a sociedade no sentido de se afirmar como grupo de relevante importância social não só na seara trabalhista, mas também na social, ecológica e humanística. 


\section{Humanos e}

Democracia

Em 2001, por ocasião da criação oficial do Movimento Nacional dos Catadores de Materiais Recicláveis, a qual foi impulsionada pelo I Congresso Nacional de Catadores realizado na cidade de Brasília, contou com a presença de representantes das diversas regiões do país. Os catadores, naquele momento, almejavam a construção de uma identidade coletiva para o grupo com o objetivo de adquirir maior representatividade de suas demandas sociais, políticas e econômicas perante o poder estatal.

Embora este evento tenha sido um marco da organização política dos catadores em âmbito nacional, o grupo já se organizava em épocas anteriores em busca de conquistas junto ao poder público. Desta forma, percebe-se que

[...] nos anos de 1980 na cidade de São Paulo que se iniciou a mobilização dos catadores, tendo como pontos de partida três marcos: a) a criação da Associação dos Catadores de Papel, Papelão e Materiais Reaproveitáveis, tendo como objetivo defender e apoiar os interesses dos catadores de papelão e promover sua organização; b) a marcha dos catadores pelas principais ruas daquela cidade, exigindo o direito à circulação dos seus carrinhos no centro da cidade e, c) a formação da primeira cooperativa de reciclagem - Cooperativa dos Catadores Autônomos de Papel, Aparas e Materiais Reaproveitáveis Ltda. (Coopamare) (LIMA, 2018, p. 4-5).

Pelo fato de o MNCR contemplar catadores(as) de todo o país, é possível reunir as forças da categoria numa única organização, as quais antes eram subdivididas em regiões menores. Ao concentrar as propostas em um movimento de grande amplitude e, por ser organizado e administrado pelos próprios destinatários dos direitos, o grupo obteve grande respaldo e legitimidade perante o Estado, permitindo várias conquistas.

Ao longo de sua trajetória de luta, o movimento não ficou restrito às questões referentes aos catadores, haja vista que o início da atividade de catação ocorre com moradores de rua, os quais buscavam, no recolhimento de materiais aptos à reciclagem, uma maneira de sobreviver. É possível observar, mesmo após tantas conquistas e o aumento de cooperativas e de associações de catadores, que ainda hoje muitos que estão nas ruas atuam nesta atividade.

Além da criação oficial do Movimento Nacional, em 2008, o I Congresso Nacional de Catadores, que mobilizou mais de 1.700 catadores(as), foi redigida a Carta de Brasília, documento que contemplava as bases do movimento e expressava "[...] as necessidades do povo que sobrevive da coleta de materiais recicláveis" (MNCR, 2018b).

Menciona-se também o apoio obtido pelos catadores de algumas instituições, tanto para a constituição do movimento nacional quanto para suas conquistas posteriores, tais como: "[...] Instituto Polis, Associação Brasileira de Engenheiros Sanitário (Abes), Cáritas Brasileira, Cempre, Pangea, Aspan [...]" (MNCR, 2012, p. 422). Saliente-se que as mencionadas instituições foram importantes "[...] no sentido de galgar conquistas para a categoria e permitir ações sérias para a proteção do meio ambiente no Brasil” (MNCR, 2012, p. 422).

A Carta de Brasília, por sua vez, apresentava propostas formuladas pelos catadores ao poder Executivo a fim de obter melhoras no exercício da atividade, bem como condições de vida digna, além de dispor acerca da necessidade da destinação de financiamentos e subsídios para a cadeia produtiva da reciclagem, bem como conferir prioridade aos "[...] projetos 
apresentados por empresas sociais de Catadores de Materiais Recicláveis, garantindo-Ihes acesso e domínio sobre a cadeia da reciclagem, como estratégia de inclusão social e geração de trabalho e renda" (MNCR, 2018b).

Outro ponto relevante da Carta de Brasília diz respeito ao tratamento dispensado à cidadania dos moradores de rua, conforme os seguintes trechos em destaque:

3.1 - Reconhecimento, por parte dos governos, em todos os níveis e instâncias, da existência da População de Rua, incluindo-a no Censo do IBGE e garantindo em lei a criação de políticas específicas de atendimento às pessoas que vivem e trabalham nas ruas, rompendo com todos os tipos de discriminação.

[...]

3.6 - Inclusão dos Moradores de Rua no Plano Nacional de Qualificação Profissional, como um segmento em situação de vulnerabilidade social, garantindo seu encaminhamento a formas de trabalho que geram renda (MNCR, 2018 b).

Reforçou-se, também, a autonomia com a qual estes atores sociais pleiteariam os seus direitos perante o poder público, ao afirmarem que o trabalho dali em diante seria em prol da "[...] erradicação do trabalho infantil e do trabalho nos lixões" e posto "[...] a serviço da preservação ambiental e da construção de uma sociedade mais justa" (MNCR, 2018b).

Ao firmar tais compromissos, o MNCR traçou alguns princípios e objetivos, os quais tomaram por base os principais anseios do grupo naquela época e, desta forma, deveriam ser perseguidos pelo movimento ao longo de sua trajetória. Como principais objetivos citam-se os seguintes:

1. A coleta de materiais recicláveis feita por catadores. Pela não privatização do lixo.

2. O pagamento aos catadores pelos serviços de coleta de materiais.

3. O controle dos catadores sobre a cadeia produtiva de materiais recicláveis.

4. A conquista de moradia, saúde, educação, creches para os catadores e suas famílias.

5. O fim dos lixões e sua transformação em aterros sanitários, com o devido deslocamento dos catadores para galpões que garantam a sobrevivência digna de todos (MNCR, 2008, p. 18).

Em relação aos princípios estabelecidos pelo MNCR, pode-se enumerar:

[...] incentivo à autogestão e organização dos catadores; independência de classe em relação aos partidos políticos, governos e empresários; luta pela gestão integrada dos resíduos sólidos, com participação ativa dos catadores; busca de tecnologias viáveis que garantam o controle da cadeia produtiva; apoio mútuo e solidariedade de classes em busca da garantia de acesso a direitos fundamentais; e luta contra a privatização dos serviços públicos de saneamento básico, incluindo os de limpeza urbana (IPEA, 2013, p. 30).

Da mesma forma, foram traçadas algumas bases de luta essenciais ao Movimento e que, em certa medida, foram capazes de abarcar os principais problemas vivenciados pelos catadores no momento de sua organização como categoria. Nesse sentido, o Movimento promove projetos educativos, como atividades recreativas, oficinas artesanais, com a finalidade 


\section{Democracia}

Humanos e

de resgatar a cultura dos catadores. Outro objeto de trabalho é a formação dos catadores, ou seja, preocupam-se em capacitar de forma adequada os atuantes na atividade de catação (MNCR, 2018c).

Priorizam-se, igualmente, as questões de saúde, educação e moradia - que constituem os principais direitos fundamentais objetivados pelo MNCR, como será trabalhado no tópico seguinte. Dessa forma, há a promoção de programas de acompanhamento comunitário dos trabalhadores em parceria com unidades de saúde pública. Em relação à educação, identificam-se programas de alfabetização popular, além da preocupação com a educação infantil (MNCR, 2018c). E, com relação à moradia, o movimento defende "[...] a prática de ocupação de espaços ociosos para fins de moradia e trabalho, além de desenvolverem mutirões autogestionários para construção de casas que buscam melhorar as condições de habitação das famílias de catadores" (MNCR, 2018c).

Nos anos de 2003 e 2005 os membros do MNCR organizaram dois Congressos LatinoAmericanos de Catadores, o primeiro realizado na cidade de Caxias do Sul e o segundo em São Leopoldo, ambas localizadas no Rio Grande do Sul.

O primeiro congresso contou com a presença de 800 catadores(as) oriundos de países como o Brasil, o Uruguai e a Argentina, os quais tinham a finalidade de partilhar experiências e dificuldades enfrentadas pela categoria ao longo dos anos de luta até a composição de um movimento social. Naquela ocasião, redigiu-se a Carta de Caxias do Sul, "[...] responsável por difundir a situação dos catadores da América Latina, visando à unificação da luta entre os países" (MNCR, 2009, p. 10).

Nesta carta constavam alguns compromissos assumidos pela categoria, os quais expressavam a relevância de eventos para discussão de questões atinentes ao grupo, como pode se identificar no trecho em destaque:

O Congresso nos ajudou a entender o que vivemos no dia a dia: fazemos parte de sociedades em que valem mais as mercadorias do que as pessoas e a natureza. Só se dá valor às coisas que se pode vender para aumentar os lucros. Tudo que sobra - até mesmo as pessoas - é jogado fora. Não se presta atenção ao que é tirado da natureza para fazer as coisas que compramos, e menos ainda ao que acontece com a natureza a partir do que se joga fora (MNCR, 2018d).

Já o segundo Congresso, realizado em 2005, teve a presença de 1.050 catadores(as) brasileiros, argentinos, uruguaios, chilenos e colombianos e diversas conquistas pelos trabalhadores foram destacadas, as quais haviam sido objeto da Carta de Caxias do Sul, mas também reafirmaram outras que ainda faziam parte das lutas do grupo, tais como:

1. Reforçar e multiplicar as Associações e as Cooperativas como bases orgânicas do Movimento, aumentando a participação com a prática da democracia direta.

$[\ldots]$

3. Avançar no processo permanente de formação e capacitação, garantindo maior autonomia nas lutas e maior capacidade para conquistar políticas públicas e novas leis que realizem nossos direitos; e de modo especial, os direitos à Previdência Social pública e os da remuneração pelo trabalho socioambiental realizado pelos catadores/as e suas organizações. 
$[\ldots]$

5. Avançar na conquista de educação de qualidade para os filhos dos catadores/as, de modo especial para que possam ficar em creches e escolas de tempo integral, para que não tenham que andar com os pais no trabalho de coleta e da reciclagem.

$[\ldots]$

6. Lutar por uma educação socioambiental nas escolas que valorize a reciclagem e fazendo a coleta seletiva com a participação dos Catadores/as (MNCR, 2018e).

A partir dos trechos transcritos, nota-se que os contornos das lutas dos catadores, desde o início de sua organização, direcionam-se à obtenção de maiores instrumentos de participação perante o poder público em busca da efetivação de seus direitos como cidadãos brasileiros, já previstos na Constituição Federal de 1988, bem como aqueles que ainda prescindem de previsão legal por falta de maior reconhecimento da categoria.

Mediante a criação de um movimento nacional formado por catadores de materiais recicláveis, este grupo social obteve significativas conquistas perante o poder público. Tais conquistas contribuíram para o reconhecimento do catador não só como um sujeito de direitos, mas também como um indivíduo que exerce um trabalho de extrema importância para toda a sociedade, haja vista os problemas ocasionados pela destinação errônea dos rejeitos sólidos. No que se refere a esta valoração dos catadores numa esfera ambientalista, Magalhães (2013, p. 250-251) comenta que

Se, de um lado, a situação que os catadores vivem pode ser lida em termos que dizem respeito à fragilidade e à vulnerabilidade, sob outro ponto de vista observamos também que essas pessoas parecem ser dotadas de um poder muito específico e interessante: 0 de transformar o lixo em mercadoria. Essa capacidade traz implicações únicas simultaneamente nos planos social, econômico e ambiental, a saber: 1) o lixo/material reciclável a ser transformado em mercadoria cristaliza as relações sociais entre as pessoas e das pessoas com ele próprio; 2) uma vez tirado do seu "destino" de descarte pelo catador, o material tem seu status transformado de "lixo" a algo que tem valor econômico; 3 ) essa reorientação no destino do material promove benefícios ecológicos para a natureza e para a sociedade.

Acerca das conquistas obtidas pelos catadores ao se organizarem em plano nacional, pode-se afirmar que "as primeiras lutas e a relação do MNCR com o Estado deram-se com vistas ao reconhecimento da profissão dos catadores de materiais recicláveis" (SILVEIRA, 2010, p. 85). Nesse sentido, as bases do movimento lutaram perante o poder público a fim de alcançar a inclusão desta atividade laboral na Classificação Brasileira de Ocupação² (CBO) elaborada pelo Ministério do Trabalho e Emprego, o que ocorreu no ano de 2002.

Com relação às demais conquistas do movimento, a Cartilha de Formação acerca dos direitos humanos elaborada pelo próprio MNCR faz a seguinte compilação:

\footnotetext{
Sob o número 5.192-5, o Ministério do Trabalho e Emprego atribui a seguinte descrição à ocupação de catador de material reciclável: os trabalhadores da coleta e seleção de material reciclável são responsáveis por coletar material reciclável e reaproveitável, vender material coletado, selecionar material coletado, preparar o material para expedição, realizar manutenção do ambiente e equipamentos de trabalho, divulgar o trabalho de reciclagem, administrar o trabalho e trabalhar com segurança (MTE, 2018).
} 


\section{Humanos e \\ Democracia}

$[\ldots]$

2. A criação de políticas municipais de coleta seletiva com a inclusão social de catadores;

3. A destinação de imóveis vazios para área de trabalho e moradia de catadores;

4. A criação do Comitê Interministerial de Inclusão Social e Econômica dos Catadores de Materiais Recicláveis (Decreto de 11/09/2003);

5. A alteração da Lei 8.666/83 (Licitações) que dispensa a licitação para as cooperativas e associações de catadores;

6. A aprovação da Lei Nacional de Saneamento 11.445 de 2007, que inicia o tratamento da política de resíduos sólidos (MNCR, 2008, p. 20).

Diante destas conquistas dos catadores como categoria de trabalhadores, vislumbra-se o mérito do movimento, além da importância de se concentrar as forças de um grupo social na busca de benefícios e de direitos perante o Estado numa organização, a qual tem por abrangência todo o país.

Por último, destaca-se que apesar de a realidade social vivenciada pelos catadores ainda ser precária, do ponto de vista da efetivação dos direitos fundamentais, tendo em vista que muitos deles ainda exercem sua atividade nas ruas, ou seja, não se encontram organizados em associações ou cooperativas, a criação do Movimento Nacional dos Catadores de Materiais Recicláveis foi um passo significativo na busca pelo reconhecimento da categoria perante a sociedade e o Estado.

\subsection{Saúde, educação e moradia como objetivos do MNCR e sua atuação}

Como visto, a Carta de Brasília elaborada em 2008 traz um rol de objetivos traçados pelo Movimento Nacional à categoria dos catadores e, entre eles, estão relacionados os direitos fundamentais à saúde, à educação e à moradia. Para ressaltar a importância desta categoria de direitos, faz-se necessária uma sucinta apresentação das principais questões que giram em torno dos direitos destacados, tanto pelas lideranças dos catadores quanto pela própria Constituição Federal de 1988, como essenciais à garantia da sobrevivência digna do indivíduo.

Em primeiro lugar, é preciso destacar que os referidos direitos encontram-se positivados no Capítulo II da Carta Magna de 1988 - o qual trata de maneira específica sobre os direitos sociais - e compõe, por sua vez, o Título II - que versa sobre os direitos e as garantias fundamentais. Desta forma, o artigo 6 da Carta Magna de 1988 classifica os seguintes direitos como sociais: "são direitos sociais a educação, a saúde, a alimentação, o trabalho, a moradia, o lazer, a segurança, a previdência social, a proteção à maternidade e à infância, a assistência aos desamparados, na forma desta Constituição" (BRASIL, 1988).

Segundo Brauner e Furlan (2013, p. 105), os direitos sociais são aqueles que

[...] nasceram fundamentados nas necessidades sociais que primam pelo estabelecimento de normas assistenciais que garantem prestações sociais estatais de cunho essencial ao indivíduo, como no caso da saúde, da assistência social, da educação, dentre outras de mesmo cunho social, as quais viabilizam a diretriz basilar para existência digna do indivíduo.

É possível afirmar que, ao serem incluídos na seção referente aos direitos fundamentais pelo constituinte de 1988, estes direitos podem ser considerados, 
[...] à luz do direito positivo-constitucional brasileiro, verdadeiros direitos fundamentais, tanto em sentido formal (pois estão na Constituição e têm status de norma constitucional) quanto em sentido material (pois são valores intimamente ligados ao princípio da dignidade da pessoa humana) (MARMELSTEIN, 2009, p. 174).

Sobre o fato de eles se relacionarem ao princípio da dignidade da pessoa humana, entende-se que - sem adentrar nas questões relativas ao significado da expressão - todos os direitos que compõem o rol do artigo 6으 da CF constituem aspectos básicos e essenciais a uma vivência de forma digna para qualquer cidadão.

Para discutir a titularidade dos direitos sociais - analisados como direitos fundamentais objetivados à concretização pela categoria dos catadores de materiais recicláveis - faz-se importante ressalvar que, apesar de o objeto dos direitos fundamentais e, neles abarcados também o dos sociais, serem direcionados a todos os seres humanos, "devemos entender que titulares são todos aqueles que necessitam de prestações relacionadas à educação, à saúde, à alimentação, ao trabalho, à moradia, ao lazer, à segurança e à previdência social" (DIMOULIS; MARTINS, 2011, p. 85).

Em outras palavras, isso significa afirmar que a titularidade dos direitos refere-se à faculdade de se demandar perante um sujeito passivo, que no caso é o Estado, a efetivação de determinado direito quando este não for previamente concretizado. De acordo com Dimoulis e Martins (2011, p. 85),

A área de regulamentação (objeto) dos referidos direitos sociais diz respeito a todos os seres humanos. A lista inclui necessidades vitais, como a alimentação e a saúde, e outras de menor premência, mas também importantíssimas, como o lazer ou a previdência social. Ora, a titularidade do direito social não é reconhecida a todos, mas tão somente às pessoas que necessitam prestação estatal para satisfazer sua respectiva necessidade.

Desta maneira, os direitos sociais devem - na perspectiva de Telles $(1998$, p. 38) - ser analisados sob a "[...] ótica dos sujeitos que os pronunciam [...]", isto é, tais direitos somente atingirão o seu real objetivo, que é sua concretização de forma igualitária perante toda a sociedade, se não forem reduzidos a direitos daquelas parcelas da sociedade que sofrem com as consequências da exclusão e da desigualdade social ou mesmo transformá-lo num direito de pessoas "carentes", mas sim como direitos universais ${ }^{3}$ que são.

\footnotetext{
"[...] desde a Declaração Universal dos Direitos Humanos, da ONU, em 1948, os direitos sociais foram reconhecidos, junto com os direitos civis e os direitos políticos, no elenco dos direitos humanos: direito ao trabalho, direito ao salário igual por trabalho igual, direito à previdência social em caso de doença, velhice, morte do arrimo de família e desemprego involuntário, direito a uma renda condizente com uma vida digna, direito ao repouso e ao lazer (aí incluindo o direito a férias remuneradas) e o direito à educação. Todos esses são considerados direitos que devem caber a todos os indivíduos igualmente, sem distinção de raça, religião, credo político, idade ou sexo. Com variações, esses direitos foram incorporados, no correr deste século, sobretudo após a Segunda Guerra Mundial, nas constituições da maioria dos países, ao menos do mundo ocidental. No Brasil, essa concepção universalista de direitos sociais foi incorporada muito tardiamente, apenas em 1988, na nova Constituição, que é uma referência política importante em nossa história recente, que foi celebrada (e hoje é contestada) como referência fundadora de uma modernidade democrática que prometia enterrar de vez 20 anos de governos militares" (TELLES, 1998, p. 36).
} 


\section{Democracia}

A autora explica que as lutas e os conflitos ${ }^{4}$ que originaram os direitos sociais,

[...] longe de se reduzirem ao puro confronto de interesses, colocam em pauta o difícil e polêmico problema da igualdade e justiça em uma sociedade dividida internamente e fraturada por suas contradições e antinomias. Por isso mesmo, ao revés de um determinismo econômico e tecnológico hoje em dia mais do que nunca revigorado, será importante reativar o sentido político inscrito nos direitos sociais. Sentido político ancorado na temporalidade própria dos conflitos pelos quais as diferenças de classe, de gênero, etnia, raça ou origem se metamorfoseiam nas figuras políticas da alteridade - sujeitos que se fazem ver e reconhecer nos direitos reivindicados, se pronunciam sobre o justo e o injusto e, nesses termos, reelaboram suas condições de existência como questões que dizem respeito às regras da vida em sociedade (TELLES, 1998, p. 38).

Nesta perspectiva, a extensão dos direitos sociais para todos os indivíduos envolve questões referentes à justiça e à igualdade, sendo justamente o equilíbrio entre estas dimensões que se persegue com a concretização desta categoria de direitos.

Compreende-se, então, que [...] a história dos direitos sociais ainda está por ser escrita, sobretudo a história da sua extensão a todos os segmentos populacionais, em atenção ao princípio fundamental da igualdade material (LEDUR, 2009, p. 80), tendo em vista que mesmo que os direitos sociais estejam positivados no texto constitucional, eles não possuem a mesma concretude quando analisados sob o ponto de vista dos seus destinatários - aqui incluídos todos os habitantes do território nacional.

Isso significa que, embora haja uma expressa previsão constitucional acerca dos referidos direitos, inclusive dentro da seara destinada aos direitos fundamentais, que são aqueles considerados indispensáveis à sobrevivência de qualquer indivíduo, ainda há um longo caminho a ser percorrido em busca da efetivação adequada dos direitos sociais.

A partir destas considerações, denota-se a importância que a atuação dos movimentos sociais, em destaque o MNCR - que trata das situações atinentes aos catadores de materiais recicláveis - tem para a potencialização dos direitos sociais relativos à educação, à saúde e à moradia. É imperioso observar, portanto, que a busca pela efetivação dos direitos sociais deve contar com a atuação dos governantes em conjunto com os representantes dos grupos sociais organizados, de maneira que aqueles que sofrem com a ausência da concretude dos direitos constitucionais levem suas demandas para os que não conhecem de perto tal realidade social.

Essa situação somente é possível em virtude de os direitos sociais contemplarem uma dupla dimensão: a subjetiva e a objetiva. Por um lado, a dimensão subjetiva dos direitos sociais diz respeito à possibilidade de os aludidos direitos serem exigidos pelos seus titulares como visto - em razão de seus respectivos destinatários. Existem, contudo, alguns obstáculos neste caminho de busca pela efetivação de direitos, por exemplo: “[...] menor densidade das

\footnotetext{
[...] direitos sociais (especialmente em se tratando dos direitos sociais básicos, como no caso da saúde, educação, previdência e assistência social e moradia, assim como no caso dos direitos dos trabalhadores a uma renda mínima, jornada de trabalho limitada, etc.) surgiram, embora resultado - como também no caso de boa parte dos direitos civis e políticos - a partir de processos de reivindicação gestados no âmbito dos movimentos sociais - como direitos assegurados por força mesmo da dignidade de cada pessoal individualmente considerada (SARLET, 2010, p. 215).
} 
normas definidoras de direitos sociais, limites ao controle judicial das políticas públicas, dependência da disponibilidade de recursos, em outras palavras, do impacto da assim chamada reserva do possível" (SARLET, 2010, p. 551).

É também sobre este ponto que emerge a necessidade da atuação dos representantes do movimento constituído pelos catadores em âmbito nacional junto ao poder público, uma vez que os referidos direitos enfrentam barreiras para a sua concretização, tais como a insuficiência de políticas públicas elaboradas pelo Estado.

A segunda dimensão dos direitos sociais, por sua vez,

[...] reflete o estreito liame desses direitos com o sistema de fins e valores constitucionais a serem respeitados e concretizados por toda a sociedade (princípio da dignidade da pessoa humana, superação das desigualdades sociais e regionais, construção de uma sociedade livre, justa e solidária) (SARLET, 2010, p. 552).

Assim, os direitos sociais devem ser efetivados em harmonia com os demais princípios previstos pela Constituição Federal, a fim de contribuir com o sistema de fins e valores constitucionais.

Com relação ao primeiro dos direitos postos em análise, Sarlet (2010, p. 276) descreve que "[...] a saúde é um bem fortemente marcado pela interdependência com outros bens e direitos fundamentais". Isto é, para que o direito à saúde atinja certo grau de concretude faz-se necessário, em contrapartida, que sejam assegurados outros direitos igualmente fundamentais.

Neste sentido, destaca-se que

[...] a saúde não importa apenas a ausência de doença ou enfermidade, pois para além da assistência médica, há também de se observar outros elementos essenciais à efetiva proteção e promoção da saúde humana, aspectos esses que abrangem a questão da renda (já que a pobreza é a maior ameaça à saúde), alimentação, habitação, educação, meio ambiente ecologicamente equilibrado, tecnologia, dentre tantos outros, o que por si só já indica uma multiplicidade de fatores envolvidos (MATEUS, 2008, p. 66).

Numa tentativa, portanto, de abarcar todos estes vértices da saúde, o constituinte de 1988 conferiu a este direito o status de direito fundamental social, ao incluí-lo no rol do artigo 60 , bem como destinou uma seção específica do texto constitucional para o seu tratamento em particular. Assim, o artigo 196 da Carta Magna dispõe que:

Art. 196. A saúde é direito de todos e dever do Estado, garantido mediante políticas sociais e econômicas que visem à redução do risco de doença e de outros agravos e ao acesso universal e igualitário às ações e serviços para sua promoção, proteção e recuperação (BRASIL, 1988).

À luz do dispositivo constitucional em análise, infere-se, em primeiro plano, que se trata de um direito destinado a todos em caráter indiscriminado, assim como os demais direitos sociais. Em segundo plano, o correspondente caráter prestacional do direito à saúde por parte do Estado, que também se constitui numa característica desta espécie de direitos. 


\section{Humanos e \\ Democracia}

O segundo direito elencado pelo MNCR, em seu programa de lutas e bases, é a educação, e sobre este direito cumpre ressaltar que foi dado um tratamento de direito fundamental de natureza social, haja vista a impossibilidade de se conceber, na atualidade, alguém que não tenha a oportunidade de acessar tal direito.

Nesse contexto, Gomes (2005, p. 92) descreve que a educação passou a ser regulada pelo Direito, "por ser imprescindível ao desenvolvimento da própria pessoa, ao afetar em vários aspectos sua vida enquanto existência e modo de ser [...]. Em razão da relevância do valor nela presente passou a significar, na esfera jurídica contemporânea, um direito fundamental".

É sabido, contudo, que apesar das reformas educacionais e sociais, hoje no Brasil ainda há titulares desse direito que não possuem o acesso a ele ou quando possuem ele não é adequado, como é o caso dos catadores de materiais recicláveis, que consiste no grupo de análise do presente trabalho.

São diversas as causas que impedem o efetivo acesso deste direito ao grupo em estudo, por exemplo, o fato de se tratar de uma população adulta com baixo índice de escolaridade - haja vista que muitos sequer possuem o Ensino Fundamental completo. Assim, não basta uma previsão constitucional acerca desse direito se a realidade retrata uma ausência de acesso às classes menos favorecidas ou mesmo esquecidas pelo poder público, sob pena de se tornar uma cláusula vazia.

Nesta perspectiva, o artigo 205 da Carta Magna estabelece que "a educação, direito de todos e dever do Estado e da família, será promovida e incentivada com a colaboração da sociedade, visando ao pleno desenvolvimento da pessoa, seu preparo para o exercício da cidadania e sua qualificação para o trabalho" (BRASIL, 1988).

Compreende-se, desta maneira, que a fundamentalidade da educação baseia-se no fato de que uma pessoa sem o acesso à educação tem a sua formação prejudicada, uma vez que não teve contato com os ensinamentos básicos, por exemplo, do que é cidadania e, assim, dificilmente ele exercerá seus direitos de forma plena, a qual é possibilitada com a formação educacional adequada.

Por último, tem-se o direito à moradia, o qual foi reconhecido, de maneira expressa, como direito fundamental social a partir da Emenda Constitucional no 26, de 14/02/2000, "em que pese a sua fundamentalidade material anteriormente reconhecida implicitamente na dicção de vários dispositivos constitucionais, tais como os artigos 24 , inciso IX, 70, inciso IV, 5, inciso XXIII, 170, inciso III, 182, §2을 183 e 191" (NASCIMENTO, 2014, p. 24).

Cabe ressaltar que, ao contrário dos outros dois direitos analisados, o direito à moradia não possui uma previsão específica no âmbito constitucional. Possui, por outro lado, seus aspectos regulamentados tão somente por legislações infraconstitucionais, como o Código Civil e o Estatuto da Cidade.

Neste ínterim, afirma-se que a abrangência do direito à moradia, mediante o seu caráter de direito fundamental social, não se restringe ao local de habitação do indivíduo, uma vez que engloba, por sua vez, todos os aspectos que influenciam a manutenção deste espaço.

Sobre esta questão, Nascimento (2014, p. 25) assevera que 
a moradia não se trata apenas de um espaço físico, sendo imperioso que ela se dê em local com condições dignas, com segurança (sem ameaça de remoção) e cercado de toda a infraestrutura de água, esgoto, transporte, dentre outros. É uma necessidade vital básica, sendo que a sua falta impede o exercício de outros direitos básicos, tais como saúde, educação, trabalho, lazer, dentre outros.

É, então, a partir deste conceito amplo que delimita o direito à moradia que está assentada a fundamentalidade de tal direito, bem como a importância da sua efetivação perante toda a sociedade. Usufruir, portanto, deste direito é - ao menos - dar condições aos indivíduos de acessarem outros direitos, tendo em vista que assim como o direito à saúde relaciona-se com outros tantos direitos fundamentais, o direito à moradia também necessita da concretização de direitos que o circundam para que possa ser garantida uma vida digna ao indivíduo.

Não restam dúvidas, portanto, acerca da fundamentalidade dos direitos sociais supracitados, haja vista a importância assumida por eles no cenário social e jurídico brasileiro, em especial os grupos sociais mais vulneráveis. Dessa forma, a realidade social brasileira, como a de exclusão enfrentada pelo grupo dos catadores de materiais recicláveis, apresenta um acesso insuficiente ou mesmo nulo dos direitos fundamentais, em virtude dos mais variados obstáculos presentes no percurso em busca de uma adequada efetivação dos direitos fundamentais, o que pode, por vezes, torná-los vazios de significado perante grande parte da sociedade brasileira.

Nota-se, a partir do contexto de lutas protagonizadas pelo Movimento Nacional de Catadores de Materiais Recicláveis que, apesar de todo esse movimento despendido para o resguardo da atividade de reciclagem e dos avanços obtidos perante a legislação brasileira, os catadores ainda enfrentam muitas dificuldades na concretização de seus direitos.

Do ponto de vista dos direitos fundamentais, pode-se afirmar que o acesso desta categoria ainda é precário e o que se vislumbra são melhorias pontuais no contexto dos catadores que atuam nas modalidades associativa e cooperativista de trabalho. Numa espécie de "inclusão às avessas", os catadores vivenciam visitas de agentes de saúde em seus locais de trabalho para a realização de palestras, exames mais simples, ou mesmo a distribuição de materiais de higiene pessoal, o que caracteriza uma tentativa de suprir as deficiências do sistema público e garantir um mínimo de acesso ao direito fundamental à saúde, por exemplo.

Por último, no que respeita à moradia, há ainda maior dificuldade na efetivação de tal direito, visto que são quase inexistentes as ações desta temática em curso. E no que se relaciona à educação, as ações são aparecem com mais frequência, uma vez que muitos trabalhadores que realizam suas atividades de forma organizada possuem acesso à Educação de Jovens e Adultos no próprio ambiente de trabalho após o encerramento do expediente profissional.

\section{CONSIDERAÇÕES FINAIS}

Ao final deste estudo é possível perceber o protagonismo assumido pelo Movimento Nacional de Catadores de Materiais Recicláveis, cujas lutas concentram-se em proporcionar a efetivação dos direitos fundamentais deste grupo social. 


\section{Democracia}

Nota-se a importância da organização da categoria dentro do rol dos "novos" movimentos sociais para as conquistas jurídicas e sociais dos grupos que representam. Nesse sentido, a formação, bem como os projetos e as lutas do movimento específico dos catadores de materiais recicláveis foram trazidos à baila para apresentar os direitos à saúde, à educação e à moradia, como direitos sociais fundamentais e cuja efetivação constitui um dos objetivos do movimento.

Observou-se que as ações concretas direcionadas à efetivação daqueles direitos fundamentais ainda são insipientes no contexto dos catadores de materiais recicláveis. Requer-se, portanto, um esforço mais efetivo da categoria profissional como um todo para que haja mais protagonismo nas pautas legislativas referentes a tais temáticas, sendo necessária uma capacitação adequada dos catadores profissionais, a fim de tomarem maior conhecimento acerca das políticas públicas direcionadas a sua categoria, além de maiores buscas por instituições parceiras com o objetivo de reduzir a precariedade com a qual estes sujeitos convivem, tanto no âmbito profissional quanto na vida privada.

\section{REFERÊNCIAS}

BENINCÁ, Dirceu. Movimento dos Catadores de Materiais Recicláveis luta pela não incineração do "lixo" e da cidadania. Revista Missões, São Paulo, 9 jun. 2012. Disponível em: http://www.revistamissoes.org.br/noticias/ ler/id/5430. Acesso em: 11 maio 2018.

BENVINDO, Aldo Zaiden. A nomeação no processo de construção do catador como ator econômico e social. 2010. 96f. Dissertação (Mestrado) - Universidade de Brasília, Centro de Estudos e Pós-Graduação sobre as Américas, Brasília, 2010.

BORTOLI, Mari Aparecida. Processos de organização de catadores de materiais recicláveis: lutas e conformações. Revista Katál, Florianópolis, v. 16, n. 2, p. 248-257, jul./dez. 2013.

BRASIL. Constituição Federal de 1988. Disponível em: http://www.planalto.gov.br/ccivil_03/constituicao/constituicaocompilado.htm. Acesso em: 9 abr. 2018.

BRAUNER, Maria Cláudia Crespo; FURLAN, Karina Morgana. O crescente processo de medicalização da vida: entre a judicialização da saúde e um novo modelo biomédico. In: BRAUNER, Maria Cláudia Crespo; FURLAN, Karina Morgana.; PIERRE, Philippe (org.). Direitos humanos, saúde e medicina: uma perspectiva internacional. Rio Grande: Furg, 2013. p. 103-132.

DIMOULIS, Dimitri; MARTINS, Leonardo. Teoria geral dos direitos fundamentais. 3. ed. São Paulo: Revista dos Tribunais, 2011.

GOHN, Maria da Glória. História dos movimentos e lutas sociais: a construção da cidadania dos brasileiros. 8. ed. São Paulo: Edições Loyola, 2013.

GOMES, Sérgio Alves. O princípio constitucional da dignidade da pessoa humana e o direito fundamental à educação. Revista de Direito Constitucional e Internacional, ano 13, n. 51, p. 53-101, abr./jun. 2005.

HERKENHOFF, João Baptista. Movimentos sociais e Direito. Porto Alegre: Livraria do Advogado, 2004.

IPEA. Instituto de Pesquisa Econômica Aplicada. Os que sobrevivem do lixo. Desafios do desenvolvimento, ano 10, ed. 77, 2013. Disponível em: http://www.ipea.gov.br/desafios/index.php?option=com_content\&view=article\&id=2941: catid=28\&ltemid=23. Acesso em: 4 ago. 2015.

LEDUR, José Felipe. Direitos fundamentais sociais: efetivação no âmbito da democracia participativa. Porto Alegre: Livraria do Advogado, 2009.

LIMA, Cristiano de França. Catadores de material reciclável em movimento: trajetória de uma identidade coletiva. Disponível em: http://www.uel.br/grupo-pesquisa/gepal/terceirosimposio/cristiano_franca_lima.pdf. Acesso em: 22 maio 2018.

MAGALHÃES, Beatriz Judice. Catadores de materiais recicláveis, consumo e valoração social. Revista UFMG, Belo Horizonte, v. 20, n. 1, p. 246-265, jan./jul. 2013.

MARMELSTEIN, George. Curso de direitos fundamentais. 2. ed. São Paulo: Atlas, 2009.

MATEUS, Cibelle Gralha. Direitos fundamentais sociais e relações privadas: o caso do direito à saúde na Constituição Brasileira de 1988. Porto Alegre: Livraria do Advogado, 2008. 
MNCR. Movimento Nacional de Catadores de Materiais Recicláveis. História do MNCR. Disponível em: http:// www.mncr.org.br/box_1/sua-historia. Acesso em: 20 maio 2018a.

MNCR. Movimento Nacional de Catadores de Materiais Recicláveis. CONGRESSO LATINO AMERICANO DE CATADORES(AS), 2. Disponível em: http://www.mncr.org.br/box_1/principios-e-objetivos/ii-congresso-latino-americano-de-catadores-as. Acesso em: 17 maio 2018 e.

MNCR. Movimento Nacional de Catadores de Materiais Recicláveis. Caminhar e resistir...: cartilha de formação. 2009. Disponível em: http://www.mncr.org.br. Acesso em: 17 maio 2018.

MNCR. Movimento Nacional de Catadores de Materiais Recicláveis. Carta de Brasília. Disponível em: http:// www.mncr.org.br/box_1/principios-e-objetivos/carta-de-brasilia. Acesso em: 17 maio 2018b.

MNCR. Movimento Nacional de Catadores de Materiais Recicláveis. Carta de Caxias do Sul. Disponível em: http:// www.mncr.org.br/box_1/principios-e-objetivos/carta-de-caxias-do-sul. Acesso em: 17 maio $2018 \mathrm{~d}$.

MNCR. Movimento Nacional de Catadores de Materiais Recicláveis. Direitos fundamentais em espécie. In: MNCR; MARINONI, Luiz Guilherme; MITIDIERO, Daniel. Curso de direito constitucional. São Paulo: Revista dos Tribunais, 2012.

MNCR. Movimento Nacional de Catadores de Materiais Recicláveis. Movimentos sociais e redes de mobilizações civis no Brasil contemporâneo. Petrópolis: Vozes, 2010.

MNCR. Movimento Nacional de Catadores de Materiais Recicláveis. Os direitos humanos e os catadores de materiais recicláveis: cartilha de formação 2008. Disponível em: www.mncr.org.br/. Acesso em: 19 maio 2018.

MNCR. Movimento Nacional de Catadores de Materiais Recicláveis. Programa de luta e organização nas bases do Movimento. Disponível em: http://www.mncr.org.br/box_1/programa-de-luta/programa-de-luta-e-organizacao-nas-bases-do-movimento. Acesso em: 17 maio 2018c.

MNCR. Movimento Nacional de Catadores de Materiais Recicláveis. Situação social das catadoras e dos catadores de material reciclável e reutilizável - Brasil. 2013. Disponível em: http://www.ipea.gov.br/agencia/images/ stories/PDFs/situacao_social/131219_relatorio_situacaosocial_mat_reciclavel_brasil.pdf. Acesso em: 11 maio 2018.

MTE. Ministério do Trabalho e Emprego. Classificação brasileira de ocupações. Disponível em: http://www.mtecbo.gov.br/cbosite/pages/home.jsf. Acesso em: 22 maio 2018.

NASCIMENTO, Bruno Pereira. Defensoria pública e regularização fundiária urbana de interesse social: novos rumos à efetivação do direito fundamental social à moradia. 2014. 90f. Dissertação (Pós-Graduação Stricto Sensu em Direitos e Garantias Fundamentais) - Faculdade de Direito de Vitória, Vitória, 2014.

SARLET, Ingo Wolfgang. A eficácia dos direitos fundamentais: uma teoria geral dos direitos fundamentais na perspectiva constitucional. 10. ed. Porto Alegre: Livraria do Advogado, 2010.

SILVEIRA, Maria Aparecida da. O Movimento Nacional de Catadores de Materiais Recicláveis: um movimento em construção 1999-2009. 2010. 144f. Dissertação (Mestrado em Serviço Social) - Pontifícia Universidade Católica de São Paulo, São Paulo, 2010.

TELLES, Vera da Silva. Direitos sociais: afinal do que se trata? Revista USP, São Paulo, n. 37, p. 34-45, mar./maio 1998.

WOLKMER, Antônio Carlos. Pluralismo jurídico: fundamentos de uma nova cultura no Direito. 3. ed. São Paulo: Alfa Omega, 2001. 